\title{
DE LA REPRESENTACIÓN CULTURAL DE LA OTREDAD A LA MATERIALIZACIÓN DE LA DIFERENCIA: ARQUEOLOGÍA CONTEMPORÁNEA DE LA DOMESTICIDAD ENTRE LOS VAQUEIROS D'ALZADA Y LOS MARAGATOS (ESPAÑA)
}

\author{
FROM THE CULTURAL REPRESENTATION OF OTHERNESS TO THE \\ MATERIALIZATION OF DIFFERENCE: A CONTEMPORARY ARCHAEOLOGY \\ OF DOMESTICITY AMONG THE VAQUEIROS D'ALZADA AND THE \\ MARAGATOS (SPAIN)
}

\author{
David González Álvarez y Pablo Alonso González $z^{2 *}$
}

\begin{abstract}
Este estudio analiza procesos contemporáneos de cambio cultural en dos áreas rurales del Noroeste de España. Ambas estuvieron habitadas por grupos sociales con una marcada identidad cultural que ha dejado su impronta en la cultura material: los vaqueiros d'alzada y los maragatos. Mediante una metodología arqueológica se analizan las casas de tres pueblos en cada caso de estudio, desvelando cómo la materialidad juega un papel fundamental en los procesos de cambio cultural. En líneas generales, se produce un tránsito entre las lógicas preindustriales de la domesticidad campesina y la concepción de la casa como un instrumento representacional que sirve para exhibir capital simbólico y social a personas de ámbitos urbanos con mentalidades individualizadas. El estudio muestra cómo la combinación de metodologías arqueológicas y etnográficas puede politizar contextos de cambio cultural contemporáneos aparentemente neutros.
\end{abstract}

Palabras claves: cambio cultural, cultura material, arqueología de los espacios domésticos, gestión del patrimonio.

This paper explores contemporary processes of cultural change in two rural areas of northwest Spain. These areas were inhabited by social groups with strong cultural identities that have made its mark in the material culture: the Vaqueiros d'Alzada and the Maragatos. The houses of three villages in each case study are analyzed through an archaeological methodology, revealing the key role materiality plays in processes of cultural change. Overall, there is a transition between preindustrial forms of peasant domesticity towards a conception of the house as a representational device used to display social and symbolic capital by highly individualized people from urban areas. The study shows how a combination of archaeological and ethnographic methodologies can politicize contemporary contexts of cultural change that are apparently neutral.

Key words: Cultural change, material culture, household archaeology, cultural heritage management.

El presente estudio analiza procesos contemporáneos de cambio cultural mediante una metodología arqueológica en dos áreas rurales del noroeste de España (Figura 1). Estas áreas estuvieron habitadas por grupos sociales con una marcada identidad cultural que ha dejado su impronta en la cultura material: los vaqueiros d'alzada y los maragatos. Nuestro trabajo busca comprender patrones de cambio cultural a través del estudio material de la domesticidad. Analizamos tres pueblos en cada caso de estudio, deteniéndonos en el análisis formal de las casas, complementando nuestra investigación con una etnografía basada en entrevistas que densifican los análisis.
¿Hasta qué punto un análisis arqueológico de la domesticidad puede arrojar luz en la comprensión de procesos contemporáneos como el abandono de lo rural, su urbanización y mercantilización, o la progresiva individualización de los sujetos contemporáneos y su asociación a formas de gobernanza neoliberales? Resulta necesario repensar las distintas formas de relación existentes entre la cultura material y la sociedad, que hasta ahora han sido tratadas como ámbitos autónomos. Es fundamental complejizar las relaciones entre los procesos de conformación identitaria, las fórmulas de gestión patrimonial y territorial, y la cultura material en el contexto de la globalización.

\footnotetext{
1 Departamento de Prehistoria, Universidad Complutense de Madrid, España. davidgon@ucm.es

2 University of Cambridge, Reino Unido.pa332@cam.ac.uk.*Autor correspondiente.
} 


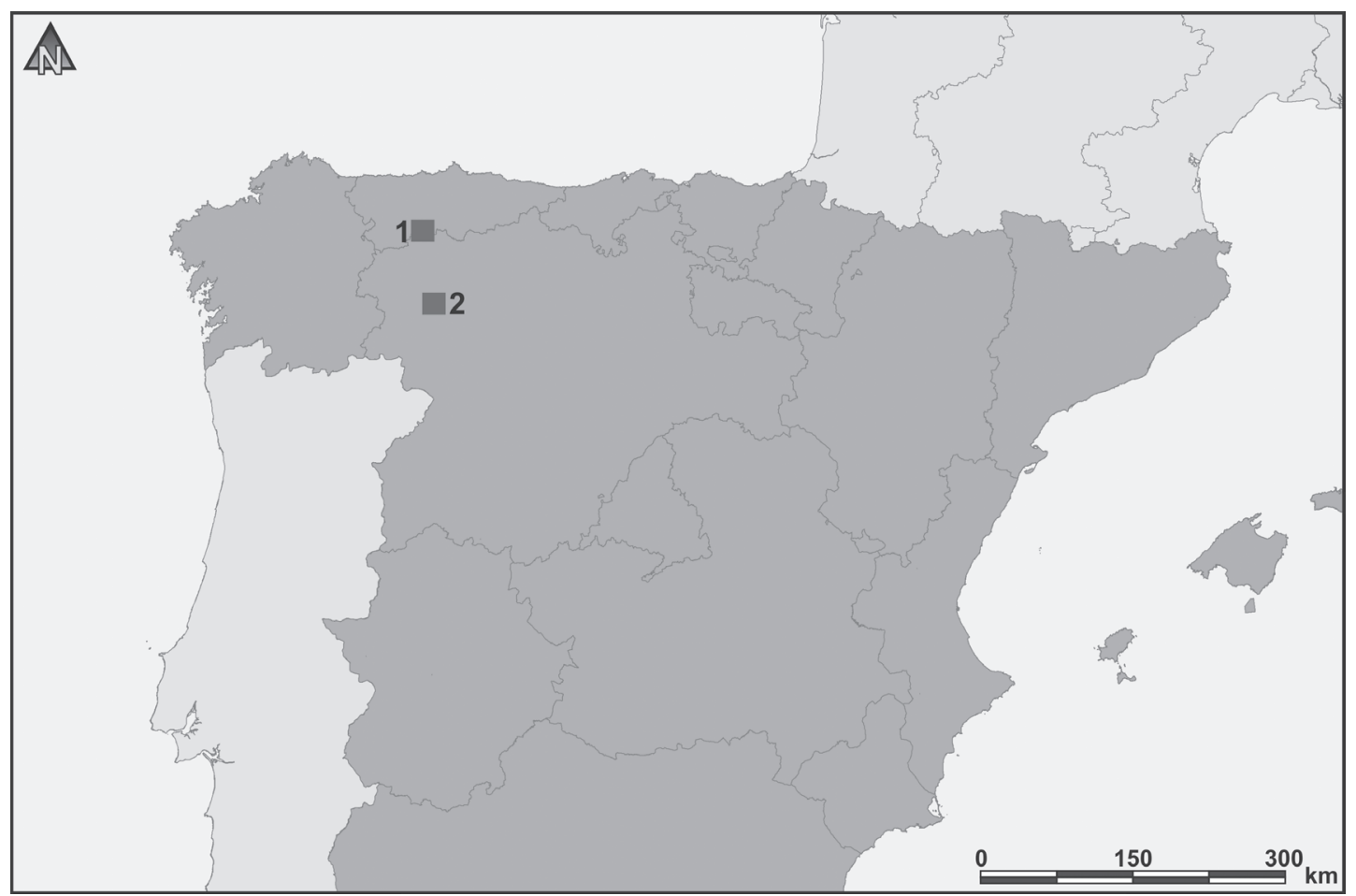

Figura 1. Casos de estudio. 1. El área vaqueira de Somiedu (Asturias). 2. El área maragata de Val de San Lorenzo (León). Case studies. 1. The vaqueiro area of Somiedu (Asturias). 2. The maragato area of Val de San Lorenzo (León).

Nuestro estudio comparativo converge con los planteamientos de la arqueología contemporánea (González Ruibal 2008b), los estudios de cultura material (Miller 1998) y las investigaciones que promueven la hibridación entre Etnografía y Arqueología (Castañeda 2008; Hamilakis 2011; Meskell 2012). Esta amplia perspectiva ha permitido comprobar cómo en los casos analizados las representaciones culturales de las identidades de estos pueblos se convierten en objetos de consumo privilegiados en un contexto global donde la diferencia aporta valor (Rullani 2006). Además, comprobamos cómo el devenir de la sociedad contemporánea hacia patrones más individualistas se manifiesta en la cultura material (Hernando Gonzalo 2012), derivando en el establecimiento de formas de relación distintas entre el ser humano y la casa, y entre el ámbito doméstico y la comunidad. Esto tiene que ver con formas de gobernanza neoliberal y raigambre urbana. Por medio de ellas se promueve la atomización de las comunidades rurales y su conversión en conjuntos de sujetos autónomos que pasan de tener una identidad relacional a una identidad individualizada basada en la acumulación y exhibición de ciertos objetos que otorgan capital simbólico y cultural.

\section{Domesticidad y Cambio Cultural}

Nuestra investigación busca complejizar nuestro entendimiento de las formas mediante las cuales cultura material y seres humanos entran en relación, teniendo en cuenta la ambigüedad, variabilidad e indeterminación de estas interacciones que se producen constantemente. Como señala Latour (2005:84), es irrealista pensar que los ensamblajes entre humanos y no humanos se produzcan a través de los distintos determinismos propuestos por la teoría social: la infraestructura económica que condiciona la superestructura en el marxismo, la materia que refleja las distinciones sociales en la sociología de Bourdieu, o que sirve como escenario donde se produce la comunicación e interacción humana según Goffman. La cultura material también es considerada desde un punto de vista funcionalista/procesualista como un medio empleado por los seres humanos para alcanzar algún fin, y desde un punto de vista hermenéutico/ 
semiótico/postprocesualista como un repositorio de significados que han de ser interpretados. Partiendo de una concepción antropológica spinoziana (Lordon 2006), consideramos que las relaciones de distinción/intercambio entre humanos se establecen a propósito de las cosas; las cosas están en el centro de la relación, pese a que el valor de estas es cambiante dependiendo de las relaciones de valorización que primen en cada organización social y período.

En último término, esta cuestión nos lleva al problema de dar cuenta de la interacción entre el "yo" interior y el "mundo exterior". Autores como Ingold (2000) o Tilley (1991) recurren a variantes fenomenológicas para concebir la relación entre el ser humano y la cultura material como un todo íntimamente ligado, mientras Miller (1998) abraza la dialéctica hegeliana. Como señala Rose (2011), todos ellos consideran la relación entre objeto y sujeto como "co-constitutiva", acusando sin embargo a Tilley de que en último término la fenomenología lleva a la primacía del "yo" que percibe el mundo exterior, y a Miller de priorizar las relaciones económicas y el consumo de objetos como modo de apropiarse simbólicamente de capital cultural, como condicionantes últimos de la relación sujetoobjeto. Igualmente, Rose se pregunta cómo se relacionan la cultura material y los seres humanos, y cómo el ser humano llega a identificarse con cierta cultura material. Consideramos que esta cuestión está mal planteada, ya que parte de una separación modernista preestablecida entre sujeto y objeto que el investigador contemporáneo proyecta a su registro y de una concepción filosófica estática del "ser".

Una vez establecida la ruptura entre objeto y sujeto surge entonces la cuestión de cómo dar cuenta de sus relaciones y suturar la distancia entre ellos. Así, el análisis de la domesticidad ha venido situando por un lado la casa dentro del ámbito de la arquitectura, y por otro a las familias que la habitan dentro de la sociología o la antropología (Haber 2011:14). Si consideramos, siguiendo a Deleuze (1993:78), que las relaciones sujeto-objeto se producen en un mundo en constante "devenir", en lugar de "ser", entenderemos que sujeto y objeto no son simplemente "co-constitutivos" el uno del otro. Son más bien subproductos de procesos no lineares ni deterministas de cambio cultural y de eventos que transforman las relaciones entre ellos: sujeto y objeto se encuentran en presuposición recíproca. Como señala Haber (2011:14): la relación entre la casa y la vida campesina no tiene que ver meramente con relaciones materiales (la casa como habitáculo residencial de la unidad doméstica) ni simbólicas (la casa como signo de la unidad doméstica). La familia y la casa están incluidos en una red relacional común en la cual devienen, junto a la chacra, las semillas, las acequias, los animales, los dioses.

Entonces, teniendo en cuenta que objetos y relaciones no se preceden ni ontológica ni temporalmente (Haber 2011:19), más que de objetos y sujetos, debemos hablar de dinámicas de objetivación y subjetivización que varían en el tiempo (Shaviro 2009:17). Así, la distinta primacía de la producción de cultura material o de su consumo cambian a medida que la sociedad y los investigadores que la reifican y analizan, devienen y se transforman planteándose preguntas diferentes. La cultura material no "refleja" los valores culturales hegemónicos, ni resulta de las relaciones de producción dominantes, sino que "deviene" con ellos y con los seres humanos que la producen, consumen y habitan, estableciendo nuevas formas de autodisciplina y educación del cuerpo (Zarankin 1999). Este devenir de la red heterogénea de relaciones en la que se ensamblan humanos y no humanos supone un cambio cultural, "una transformación de la manera en que las personas se relacionan con el mundo" (Hernando Gonzalo y González Ruibal 2011:9) y con los objetos.

Siguiendo a Haber (2011:26-27), detectamos así una transición de la casa como "sedimento" a la casa como "monumento". En el polo de la tradición arquitectónica vernácula encontramos casas que resultan del crecimiento orgánico y la deposición cotidiana de objetos derivados de procesos productivos e interacciones socioculturales, donde "las sendas espacio-temporales de la cotidianeidad diaria y la biografía individual se inscribe en sucesiones diacrónicas de un tiempo más largo" (Haber 2011:26-27). En cambio, los sujetos posmodernos e individualizados tienden a concebir las casas como monumentos, eventos fundacionales que reensamblan la diacronía pretérita para situarla fuera del tiempo y pasar a funcionar como metáfora o símbolo de una individualidad. Esto incluye la restauración de casas antiguas como resignificación de acumulaciones de sedimentos o la construcción de casas nuevas que se parecen a las antiguas como 
creación de monumentos ex nihilo. Las casas y las personas devienen así en complejas relaciones con ritmos y temporalidades diversas, ensamblándose con tradiciones locales y/o hibridándose con jerarquías globales de valor que funcionan como metapatrones culturales (Herzfeld 2010).

\section{Métodos}

En la última década se han llevado a cabo en España trabajos similares al que aquí presentamos bajo el paraguas de la Etnoarqueología (Alonso González 2009; González Álvarez 2011; González Ruibal 2003a, 2005). Siguiendo a González Ruibal (2008b), creemos necesario abandonar dicho concepto por las connotaciones negativas derivadas de su uso por la Arqueología procesual (Hernando Gonzalo 2006). Esta estudiaba comunidades preindustriales en búsqueda de analogías que apoyasen la interpretación del registro arqueológico (p.ej., Binford 1978), en la mayor parte de los casos sin interés en los procesos de cambio contemporáneos de las sociedades estudiadas ni reflexión alguna sobre su subalternización en el contexto de la globalización (González Ruibal 2008a). Creemos necesario considerar las comunidades estudiadas, sus procesos de cambio y los contextos sociopolíticos en los que se encuadran como fines en sí mismos, en lugar de utilizarlas como medios para el desarrollo epistemológico de la disciplina. En este sentido, preferimos hablar de la aplicación de metodologías arqueológicas políticamente informadas a un contexto contemporáneo en el que lo rural preindustrial se intersecciona con patrones globales capitalistas y urbanos de diversa índole (Buchli y Lucas 2001). De hecho, la arqueología estudia los seres humanos a través de la cultura material, trascendiendo límites de orden geográfico o cronológico. Complementamos nuestra metodología con análisis etnográficos y antropológicos que dan lugar a una metodología híbrida. Así, consideramos legítimo recurrir a entrevistas y a "utilizar las fuentes etnográficas que hacen referencia explícita al mundo de los artefactos para tratar de adentrarse en cuestiones sociales o simbólicas relacionadas con esos objetos" (González Ruibal 2003b:160).

La estrategia principal de nuestra investigación consistió en realizar un inventario de cada casa en las seis poblaciones estudiadas, a partir de la creación de categorías de cada construcción adecuadas para nuestras necesidades analíticas, y efectuando un análisis formal de las mismas ${ }^{1}$. Examinamos la apariencia externa de las construcciones, las formas y materiales constructivos, y los ornamentos presentes en puertas, ventanas, tejados, vallas, etc. Por su parte, el análisis de la espacialidad micro nos permitió valorar patrones de accesibilidad, privacidad y actividades productivas o funcionales (huertos, establos, garajes) y de ocio (jardines, piscinas). En cuanto a la espacialidad macro, exploramos la conformación de los paisajes y economías visuales de los pueblos, atendiendo a la distribución de las casas mediante análisis espaciales realizados con Sistemas de Información Geográfica.

Además, el trabajo etnográfico nos permitió densificar las observaciones arqueológicas de estos procesos diacrónicos de cambio cultural. Por un lado, realizamos entrevistas de carácter informal y/o semiestructurado con propietarios de las casas, sacando a colación temas centrales para nuestro estudio a la vez que dejábamos espacio para la libre expresión del entrevistado (Sørensen 2009). Las entrevistas buscaban conocer la visión de los actores locales respecto de estos procesos de cambio y entender los valores que subyacen a las transformaciones en la materialidad de las casas a largo plazo. Por otro lado, observamos antropológicamente los distintos ritmos, patrones externos e internos de movilidad geográfica, y en general las dinámicas sociales y relaciones de poder presentes en los pueblos. Finalmente, consideramos cómo las normativas urbanas y patrimoniales condicionaban las formas de relacionalidad existentes entre los espacios domésticos, las personas y la comunidad.

\section{Casos de Estudio}

Los casos de estudio seleccionados comparten una serie de rasgos socioculturales que les convierten en ejemplos apropiados para el estudio del cambio cultural a través de la materialidad. Los maragatos y los vaqueiros d'alzada constituyen grupos de difícil caracterización. Ambos han sido incluidos entre los denominados "pueblos malditos" españoles, junto con los gitanos, los agotes, los chuetas y los pasiegos (Miner Otamendi y Martínez 1978). Por esta razón han recibido atención prioritaria de antropólogos, historiadores y etnógrafos, tanto españoles como extranjeros. Como tales, han sido sometidos a una construcción social que los situaba como referentes de otredad durante el proceso de creación del estado nacional español a partir de la Ilustración (siglos XVIII-XIX). Diferentes autores (Acevedo y Huelves 
1893; Lardizábal y Uribe 1786; Sarmiento 1787) los consideraron descendientes de moros, tribus celtas, cartagineses, germanos, judíos... enfatizando su diferencia identitaria respecto de otros grupos sociales "españoles" con los que cohabitaban. La construcción social de la representación cultural de ambos grupos continuó con la labor de la antropología física, con estudios de cráneos (Aragón y Escacena 1902), seroantropología (Hors 1951), huellas dactilares (Egocheaga Rodríguez y García González 2003) o ADN (Larruga et al. 2001). Pese a que los resultados no confirmaban su diferencia biológica, la antropología sociocultural continuó situando estos grupos como temas centrales de su investigación (Caro Baroja 2003; Cátedra Tomás 1989; Melis Maynar 1987). Igualmente, el resurgir folklórico impulsado por la dictadura franquista (1939-1975) para territorializar las identidades locales y difuminar los nacionalismos periféricos (Ortiz García 1999; Viejo-Rose 2011) otorgó a las representaciones culturales de ambos pueblos un protagonismo singular, lo que contribuyó a la difusión de sus expresiones culturales, ya reificadas $\mathrm{y}$ codificadas.

Aunque la deconstrucción antropológica de esta diferencia se produjo a partir de la década de 1970 en el caso de los vaqueiros d'alzada (García Martínez 1988), y más tímidamente en el caso maragato tras la década de 1980 (Rubio Pérez 2003), su inercia como referente mítico dentro del imaginario popular y académico sigue viva. Desde la Edad Moderna, ambos grupos presentaban una gran movilidad geográfica vinculada a su dedicación al comercio, a tiempo completo entre los maragatos, complementada con ganadería trashumante entre los vaqueiros. Esta ocupación les daba acceso a unos recursos monetarios de los que carecían las sociedades fundamentalmente campesinas entre las que vivían. Estos factores llevaron a su aislamiento social, potenciado por motivos internos (endogamia matrimonial, preservación de capitales y rentas) y externos (marginación sancionada por la iglesia). Todo esto contribuía a incrementar la percepción social de su diferencia, reforzada por la particularidad de sus vestimentas, folklore, costumbres y cultura material.

El estudio de Callahan (1972) muestra cómo, desde el siglo XVIII, se produjo en España el auge de la burguesía y la decadencia de la clase aristocrática, lo que llevó a conflictos relacionados con cuestiones de sangre, honor y comercio. En el contexto de la Contrarreforma, las dedicaciones comerciales y la voluntad de enriquecerse eran consideradas pecaminosas para el catolicismo, atribuidas a judíos y protestantes (Freeman 2011). Por tanto, no es casual que los "pueblos malditos" españoles compartan una dedicación al comercio y cierta movilidad geográfica. Se entiende así que estos grupos fueron considerados los "otros internos" que reforzaban la identidad central española en el proceso de construcción de la identidad nacional; no podían ser ni cristianos ni españoles, y consecuentemente se atribuía su origen a grupos no españoles.

Paradójicamente, estos procesos de construcción social de la diferencia se produjeron en paralelo a la obliteración de la alteridad real de estos grupos. En el caso de los vaqueiros d'alzada presentes en el municipio de Somiedu, este colectivo tiende a homogeneizarse con el resto de la población campesina de sus propias comunidades, difuminándose así las diferencias en términos socioeconómicos y culturales (González Álvarez 2011). Del mismo modo, los maragatos que habitaban Val de San Lorenzo emigran durante la primera mitad del siglo XX de forma masiva por lo que se diluyen las diferencias de las familias que se quedan respecto de las comunidades campesinas con las que cohabitan (Alonso González 2013).

Pese a la descomposición social de estos grupos, su cultura material -especialmente su arquitectura doméstica- permanece en sus áreas de origen, lo que facilita su estudio desde una perspectiva arqueológica. Esta materialidad está sujeta a distintos procesos actuales de modificación, reinterpretación y capitalización cultural en un contexto económico posindustrial asociado al auge del fenómeno de la segunda vivienda, el turismo cultural y la economía del ocio. Estos cambios van asociados a la llegada de nuevos habitantes a los pueblos estudiados con nuevas formas de vivir y de entender la materialidad de la casa. Precisamente, la existencia de una representación cultural de la diferencia de maragatos y vaqueiros funciona como elemento atractor para compradores de segunda vivienda, inversores inmobiliarios y turistas, pues en la economía posindustrial la diferencia otorga valor (ver Alonso González 2013).

Partiendo de este contexto, hemos analizado cuantitativa y cualitativamente la arquitectura de seis poblaciones, tres en el municipio de Val de San Lorenzo (León) y tres en el área vaqueira del municipio de Somiedu (Asturias) (Tabla 1). Basándonos en criterios estéticos, formales y 
Tabla 1. Muestra estudiada en ambos casos de estudio, con la relación entre casas y habitantes. Sample studied in our case studies, showing the ratio between houses and inhabitants.

\begin{tabular}{lccc}
\hline \multicolumn{4}{c}{ Caso 1: } \\
\hline Localidad & Habitantes (2012) & Casas analizadas & Relación Hab./casas \\
\hline El Puertu & 72 & 111 & 0,65 \\
La Peral & 23 & 55 & 0,42 \\
L.lamardal & 26 & 19 & 1,37 \\
\hline \multicolumn{5}{l}{ Caso 2: } \\
\hline Localidad & Casas analizadas & Relación Hab./casas \\
\hline Val de San Lorenzo & 476 & 348 & 1,37 \\
Val de San Román & 62 & 120 & 0,51 \\
Lagunas de Somoza & 40 & 116 & 0,34 \\
\hline
\end{tabular}

funcionales, elaboramos una clasificación asumiendo que ninguna casa coincide enteramente con una categoría concreta: se trata de una gradiente de intensidad, y cada casa solo se aproxima a la categoría asignada como un límite abstracto. Esta tipología, lejos de pretender dar una visión estática y evolucionista de la domesticidad, responde a los distintos ritmos, tendencias y temporalidades de los procesos culturales en marcha. Simplificando la cuestión al máximo, nos encontramos con un contexto sociocultural en transición de un mundo preindustrial tradicional rural a una posmodernidad donde predominan criterios urbanos e individualistas, pasando por una infinita multiplicidad de situaciones intermedias dentro de lo que podríamos considerar como modernidad ${ }^{2}$.

Estas consideraciones nos llevan a establecer las siguientes categorías:

- La "casa tradicional" (Figura 2) presenta formas características de la arquitectura vernácula. Tiene un carácter eminentemente funcional y emplea materiales locales: piedra, madera, teja artesanal. Muchas casas en esta categoría están deshabitadas, siendo usadas como establos o pajares.

- La "casa tradicional en transición a la modernidad" (Figura 3) incorpora modificaciones formales y funcionales a la casa tradicional. Surgen nuevos espacios de forma orgánica (baños, cocheras, vestíbulos) y se emplean nuevos materiales (cemento, ladrillo, teja industrial, plástico, cubiertas de fibrocemento). Se percibe una tendencia creciente a la separación espacial entre humanos y animales.
- La "casa moderna" (Figura 4) implica la proyección racional de la vivienda a partir de lógicas que adscriben ciertos espacios a funciones específicas preestablecidas. Se emplean materiales constructivos modernos de tipo industrial. Se incluyen casas de nueva planta y ejemplos donde se ha producido la remoción/ remodelación casi total de las estructuras preexistentes. La casa busca "urbanizar" su aspecto formal, asignando espacios totalmente separados para los animales y creando espacios no productivos en su entorno, como jardines.

- La "casa restaurada" (Figura 5) es una casa tradicional, en buen estado de conservación $o$ en ruinas, que se remodela de acuerdo con criterios estéticos que racionalmente buscan realzar los elementos rurales vernáculos con lógicas patrimonializadoras que intentan preservar un aura de autenticidad.

- La "casa posmoderna" (Figura 6) es una construcción de nueva planta, concebida y construida con técnicas y materiales modernos. Se establece una vinculación simbólica con lo vernáculo a través del recubrimiento de los materiales modernos (ladrillo, cemento) con piedra o con la reutilización de puertas y ventanas antiguas o tejas artesanales. Suelen ornamentarse con detalles de forja, tallas en madera, etc.

- La "casa en ruinas" (Figura 7) es producto del éxodo rural, acentuado en ambas zonas desde finales del siglo XIX. Estas construcciones pueden tener usos funcionales ocasionales como corrales o huertas. 


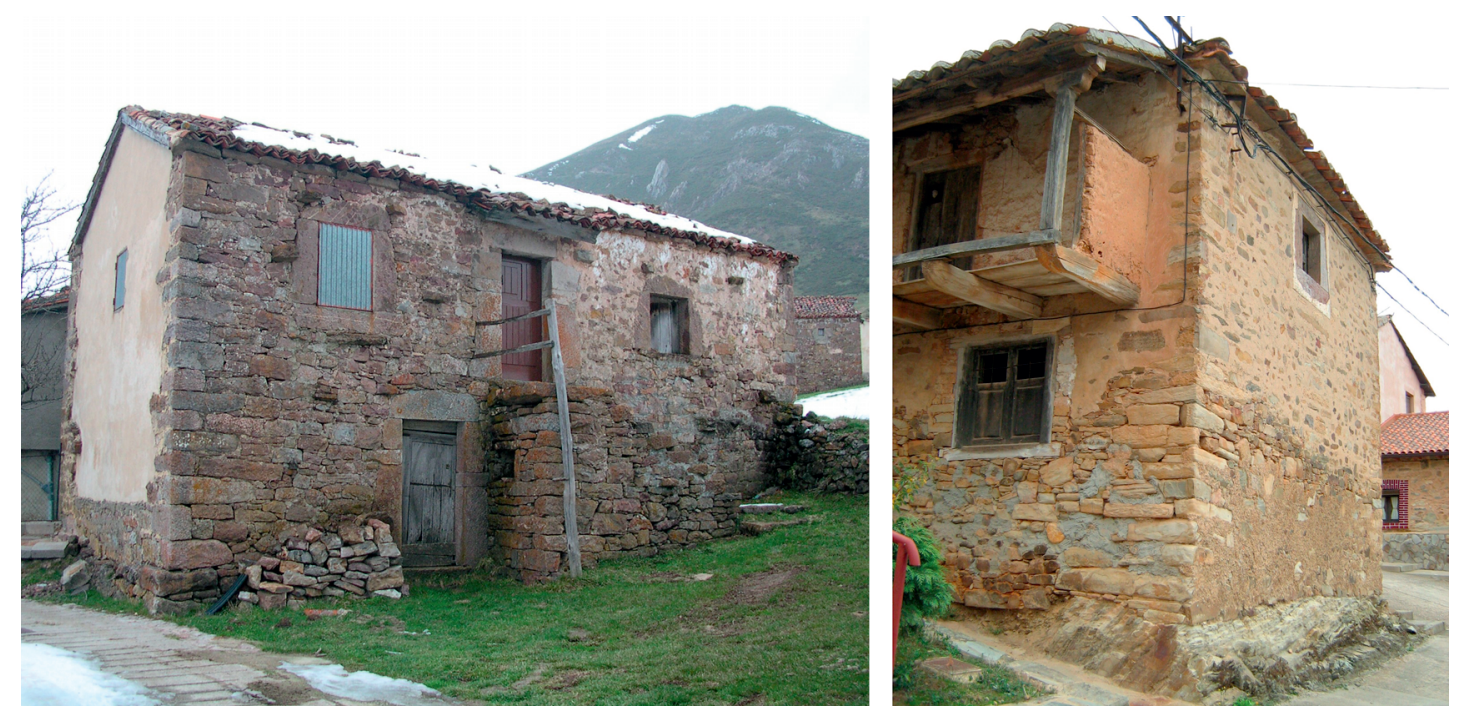

Figura 2. Casas tradicionales de La Peral (izquierda) y Val de San Lorenzo (derecha).

Traditional houses in La Peral (left) and Val de San Lorenzo (right).

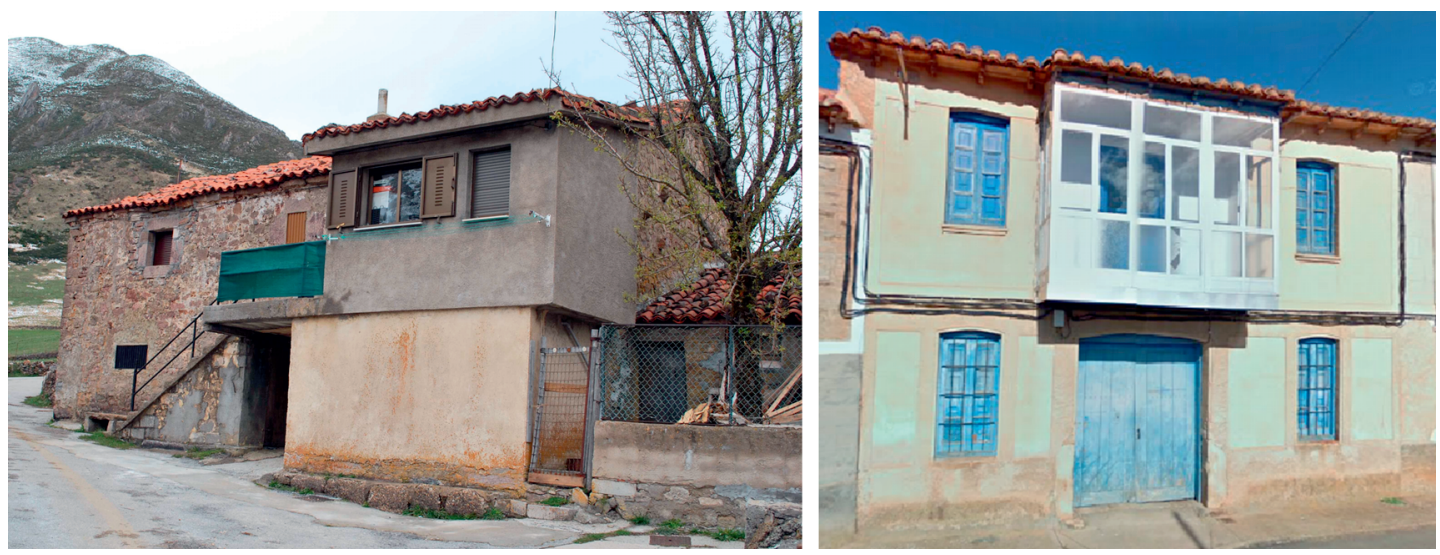

Figura 3. Casas en transición a la modernidad de La Peral (izquierda) y Val de San Román (derecha).

Houses in transition to modernity in La Peral (left) and Val de San Román (right).
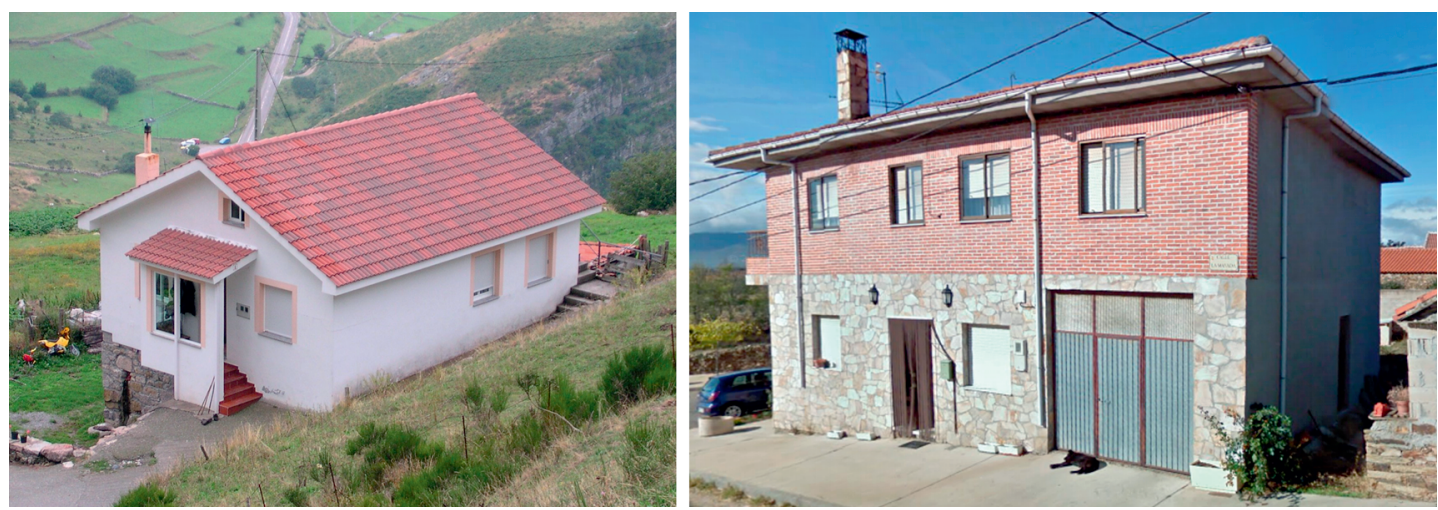

Figura 4. Casas modernas de L.lamardal (izquierda) y Lagunas de Somoza (derecha).

Modern houses in L.lamardal (left) and Lagunas de Somoza (right). 

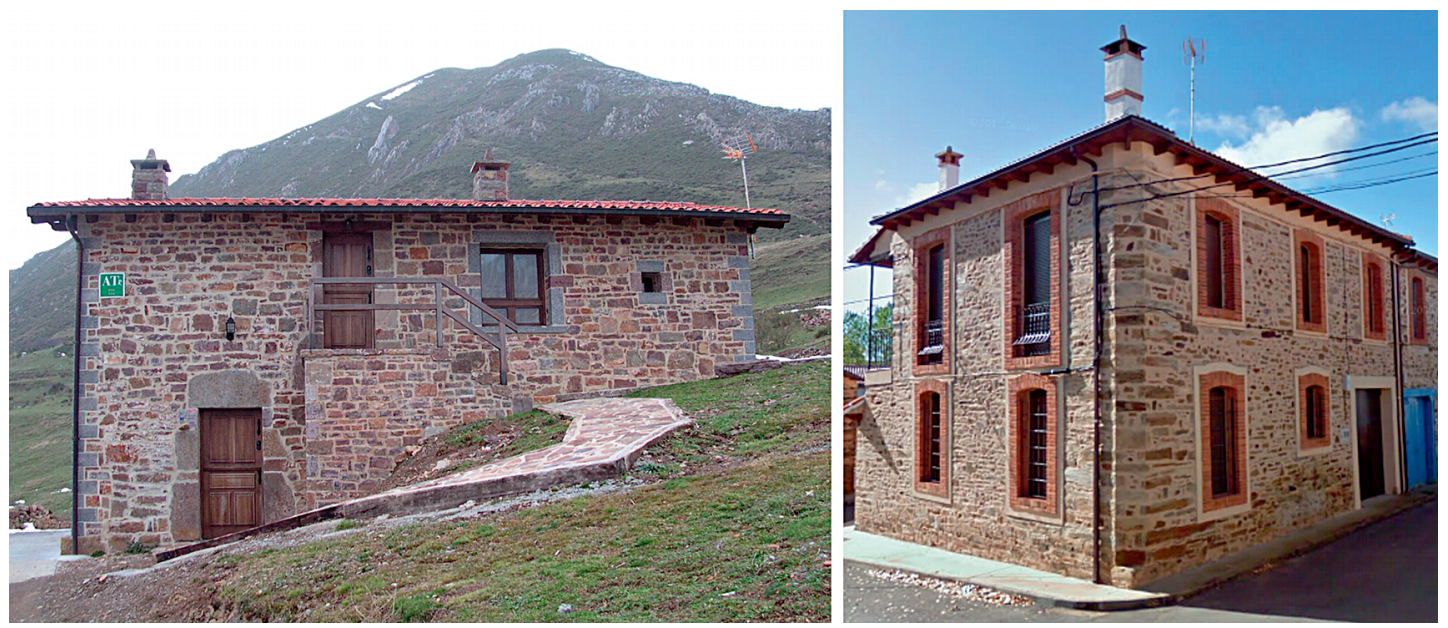

Figura 5. Casas restauradas de La Peral (izquierda) y Val de San Román (derecha). Restored houses in La Peral (left) and Val de San Román (right).
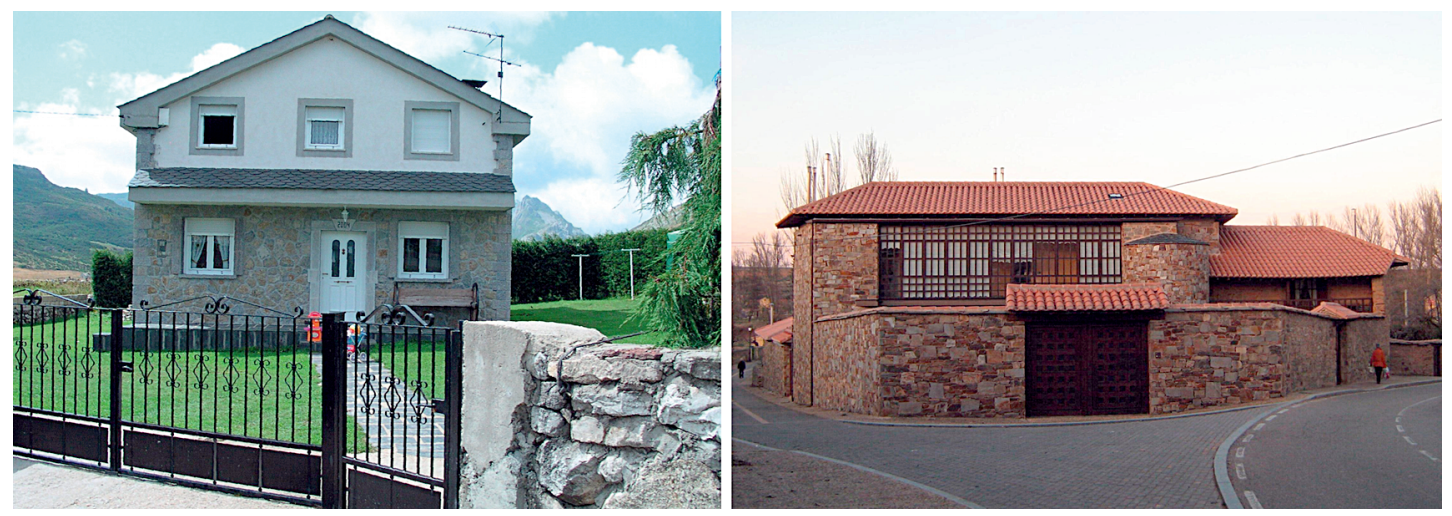

Figura 6. Casas posmodernas de El Puertu (izquierda) y Val de San Lorenzo (derecha).

Postmodern houses in El Puerto (left) and Val de San Lorenzo (right).
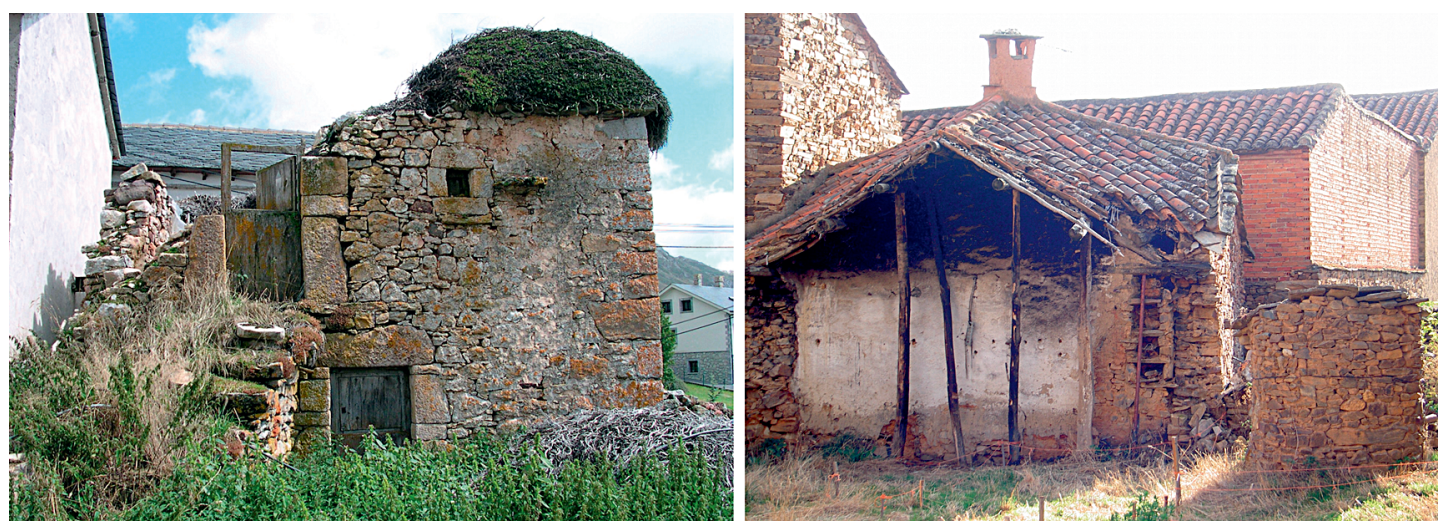

Figura 7. Casas en ruinas de El Puertu (izquierda) y Val de San Lorenzo (derecha).

Ruined houses in El Puerto (left) and Val de San Lorenzo (right). 
- El "edificio industrial" (Figura 8) es una edificación no doméstica construida con materiales y técnicas modernas. Tienen funcionalidades relacionadas con la industria artesanal o la agricultura y la ganadería intensificadas.

\section{El área vaqueira de Somiedu}

Este estudio comprende tres pueblos del municipio asturiano de Somiedu: El Puertu (Figura 9), La Peral y L.lamardal. Estas localidades estaban tradicionalmente habitadas de forma estacional entre marzo y noviembre por familias trashumantes pertenecientes al colectivo de los vaqueiros d'alzada. Todas ellas reflejan el declive demográfico del ámbito rural del noroeste de España a lo largo del siglo XX, parejo al proceso de desarticulación de los modos de vida campesinos y la modernización de las formas de producción agrarios. Como resultado de la intersección de diversos procesos sociohistóricos, el ámbito de la domesticidad presenta una gran variabilidad en su materialidad que puede relacionarse con las dinámicas culturales cambiantes de su biografía reciente (Tabla 2).

La ganadería trashumante constituía la actividad primordial de los vaqueiros. La extensión de la Política Agraria Común en el último tercio del siglo XX aceleró su abandono, al tiempo que se impuso una producción ganadera intensificada y mecanizada, adoptada por algunas familias que se apoyarían en subvenciones de la Unión Europea. El éxodo rural se redobló tras el ingreso de España en el Mercado Común Europeo, lo cual deriva en una masiva presencia de casas deshabitadas o arruinadas (con un 10,9\% de ruinas en La Peral, un $36,8 \%$ en L.lamardal o un $4,5 \%$ en El Puertu) en el caso de estudio.

El tránsito entre las formas culturales preindustriales y la modernidad capitalista actual se refleja en las casas en transición (un 25,5\% en La Peral, un 10,5\% en L.lamardal y un $28,8 \%$ en El Puertu) y las casas modernas (un 5,5\% en La Peral, un 21,1\% en L.lamardal y un $13,5 \%$ en El Puertu), muchas de ellas habitadas por familias con antecedentes trashumantes, hoy sedentarizadas, que desarrollan actividades ganaderas intensificadas. Algunas transformaron de manera orgánica y paulatina sus viviendas, asimiladas a nuestra categoría de casa tradicional en transición a la modernidad. De este modo, se van adosando nuevos volúmenes a las casas tradicionales para instalar baños o guarecer tractores. En su construcción se emplean nuevos materiales como ladrillos industriales u hormigón, que contrastan con los paramentos tradicionales de piedra. Tal y como mostraron las entrevistas, estos materiales son altamente valorados por los habitantes de estas casas. Por su parte, los grandes rebaños de la producción ganadera modernizada se mantienen semiestabulados en casas tradicionales deshabitadas reaprovechadas como establos o en edificios industriales de nueva planta (sobre todo destacables en el caso de El Puertu, con un 9,9\% de presencia).

Más allá de las necesidades espaciales que surgen con las nuevas formas de producción, viejos ámbitos del entorno doméstico son reinterpretados. Su análisis arqueológico permite señalar el activo papel de la cultura material en estos procesos de cambio. Por ejemplo, muchas familias abandonan o reducen la importancia de los pequeños huertos situados en el entorno de las casas que les servían
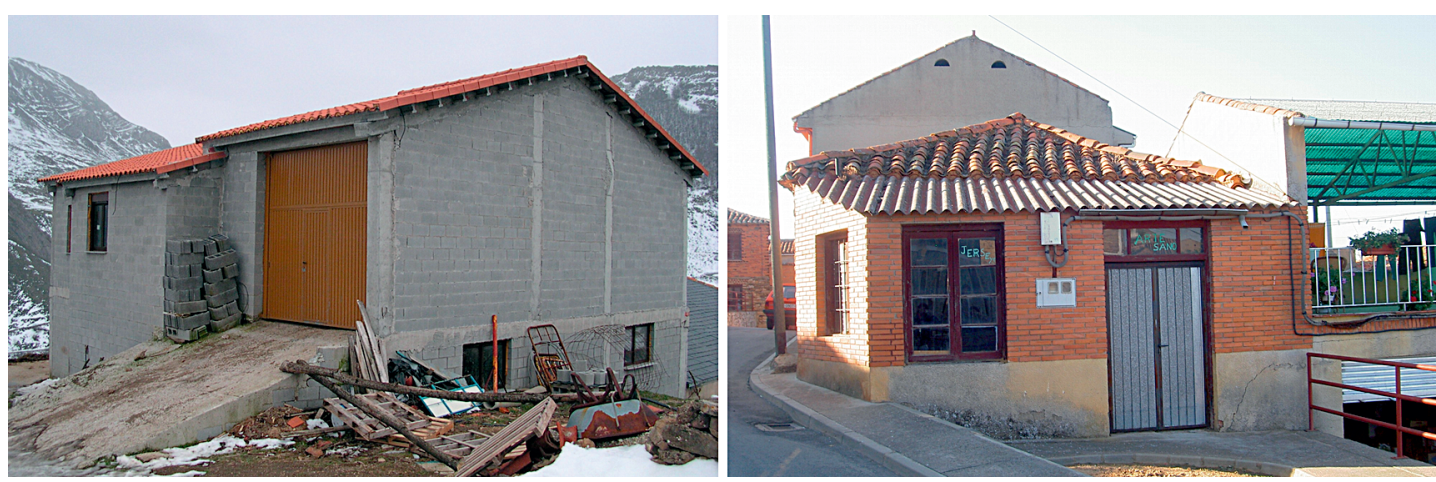

Figura 8. Edificios industriales de La Peral (izquierda) y Val de San Lorenzo (derecha).

Industrial buildings in La Peral (left) and Val de San Lorenzo (right). 


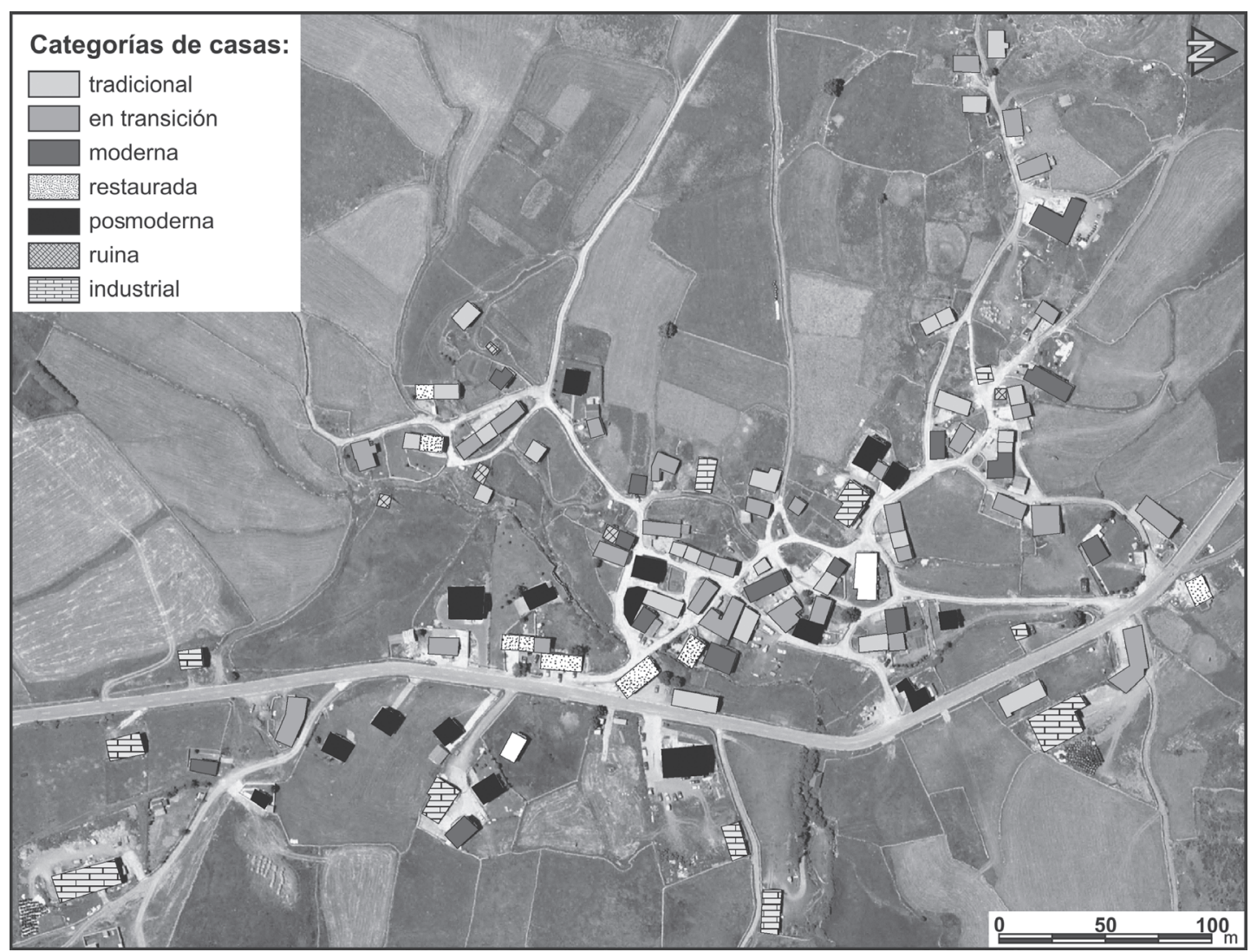

Figura 9. Plano de El Puertu con la distribución de las casas analizadas según las categorías establecidas. Map of El Puertu with the spatial distribution of the houses studies according to our categories.

Tabla 2. Casas por categorías en el caso de estudio de Somiedu (Asturias). Houses by category in the case study of Somiedu (Asturias).

\begin{tabular}{lcccccccc}
\hline & $\begin{array}{c}\text { Casas } \\
\text { tradicionales }\end{array}$ & $\begin{array}{c}\text { Casas en } \\
\text { transición }\end{array}$ & $\begin{array}{c}\text { Casas } \\
\text { modernas }\end{array}$ & $\begin{array}{c}\text { Casas } \\
\text { restauradas }\end{array}$ & $\begin{array}{c}\text { Casas } \\
\text { posmodernas }\end{array}$ & Ruinas & $\begin{array}{c}\text { Edificios } \\
\text { industriales }\end{array}$ & Total \\
\hline La Peral & 21 & 14 & 3 & 5 & 5 & 6 & 1 & 55 \\
& $28,2 \%$ & $25,5 \%$ & $5,5 \%$ & $9,1 \%$ & $9,1 \%$ & $10,9 \%$ & $1,8 \%$ & $100 \%$ \\
L.lamardal & 3 & 2 & 4 & 2 & 0 & 7 & 1 & 19 \\
& $15,8 \%$ & $10,5 \%$ & $21,1 \%$ & $10,5 \%$ & $0 \%$ & $36,8 \%$ & $5,3 \%$ & $100 \%$ \\
El Puertu & 25 & 32 & 15 & 8 & 15 & 5 & 11 & 111 \\
& $22,5 \%$ & $28,8 \%$ & $13,5 \%$ & $7,2 \%$ & $13,5 \%$ & $4,5 \%$ & $9,9 \%$ & $100 \%$ \\
\hline
\end{tabular}

para autoabastecerse de hortalizas. Estos se transforman en pequeños jardines a modo de espacios de representación, con setos ornamentales y aperos de labranza tradicionales que, aparentemente olvidados, languidecen oxidados desprovistos de su utilidad pretérita. Tales elementos funcionarían como metáforas del exitoso cambio cultural y productivo, y del triunfo de lo urbano frente a lo rural. Por supuesto, encontramos situaciones intermedias igualmente reveladoras, como la presencia de pequeños huertos de berzas o patatas en la parte trasera de algunas casas modernas o en transición a la modernidad, señal del dinamismo y variabilidad de los procesos de cambio cultural, algo también observado en la vecina Galicia por González Ruibal (2003a). 
A finales del siglo XX, el municipio de Somiedu fue declarado Parque Natural, produciéndose un auge del turismo que contrarrestó su declive económico y demográfico. Se desarrollaron iniciativas para la puesta en valor del patrimonio natural y cultural financiadas con fondos europeos que fomentaron la instalación de casas rurales, museos o rutas de montaña. Consecuentemente, el área se convirtió en un importante foco para el turismo, destino además de familias procedentes del ámbito urbano que compraron, restauraron o construyeron segundas residencias. El auge del turismo rural y el fenómeno de la segunda vivienda se reflejan en la presencia de casas restauradas (un 9,1\% en La Peral, un $10,5 \%$ en L.lamardal y un 7,2\% en El Puertu) y posmodernas (fundamentalmente visibles en $\mathrm{La}$ Peral y El Puertu, con una presencia del $9,1 \%$ y el $13,5 \%$, respectivamente).

Mientras la mayor parte de las viviendas destinadas al turismo rural se corresponden con casas restauradas, los ejemplos de segundas viviendas se reparten entre casas restauradas y posmodernas. En ambos casos, la domesticidad se aleja de las funciones y usos tradicionales, alcanzando la consideración de "monumento" (cf. Haber 2011:26-27). Normalmente, los parámetros formales ligados a la arquitectura tradicional vaqueira son conservados y ensalzados en las casas restauradas: uso de mampostería de piedra, aleros de madera, escaleras exteriores de piedra adosadas a la fachada principal, etc. El apego por lo vernáculo y la búsqueda de la autenticidad son valores importantes para los empresarios del turismo rural, para quienes la representación cultural abstracta de "lo vaqueiro" supone un valor añadido que singulariza su producto en el mercado turístico, lo cual puede conectarse con la generalización del etnocomercio (Comaroff y Comaroff 2009). Significativamente, el cumplimiento con patrones arquitectónicos "tradicionales" resulta obligatorio para obtener subvenciones de fondos europeos de desarrollo rural.

En el caso de las casas posmodernas obtenemos pautas divergentes, ya que las representaciones culturales recreadas en la domesticidad no refieren exclusivamente a la tradición vaqueira. Más bien se relacionan con metapatrones que materializan representaciones culturales genéricas del mundo campesino o de un ideal rural abstracto. Efectivamente, si consideramos que las casas posmodernas materializan las identidades altamente individualizadas de sus propietarios, resulta lógico que busquen formas monumentales. Por ello, la arquitectura tradicional vaqueira -simple, monótona y poco monumental- no sirve como referente de prestigio que exalte suficientemente la individualidad. Así, es posible observar en algunas casas posmodernas de El Puertu y La Peral motivos decorativos no vaqueiros procedentes del medio rural asturiano, entremezclados con símbolos derivados de mitologías célticas contemporáneas o lámparas instaladas dentro de madreñas (zuecos de madera) iluminando jardines en los que se exhiben viejos arados reconvertidos en maceteros, o teitos (cabañas tradicionales con cubierta vegetal) transformados en cenadores. Esta conjunción de elementos diversos crea escenografías híbridas donde la materialidad confluye con la creciente complejidad identitaria de la posmodernidad. Así, personas de procedencia urbana se sirven de la cultura material para vincularse a discursos patrimoniales globales, utilizando a la vez símbolos locales que añaden capital simbólico vinculado a sus identidades e incrementan el valor monetario de sus propiedades inmuebles.

En las casas posmodernas prima la voluntad de exhibición frente al utilitarismo y la adaptación a los condicionantes ambientales. Observamos así casas construidas con paredes de ladrillos recubiertas de piedra, arquitecturas en madera, ventanales amplios, porches y terrazas, etc. Todos estos rasgos escenifican la intencionalidad monumentalizadora de sus moradores altamente individualizados, que contrasta con el ethos igualitario imperante en la domesticidad preindustrial. En aquel marco sociocultural, lo colectivo o las fórmulas intragrupales de ayuda mutua eran rasgos centrales en la configuración de sus mecanismos identitarios de seguridad. Aspecto que cambia con la modernidad capitalista actual, donde las fórmulas identitarias basculan hacia el individualismo (Hernando Gonzalo 2012). Ambos extremos se entrecruzan con la domesticidad en el caso de estudio. Mientras las casas tradicionales ofrecen una alta accesibilidad, sin vallas ni cierres perimetrales, las casas posmodernas presentan una multiplicidad de elementos que restringen el acceso y la visibilidad del núcleo doméstico: verjas metálicas, setos, vestíbulos, etc.

\section{El área maragata de Val de San Lorenzo}

El municipio de Val de San Lorenzo es uno de los seis que comprende la comarca de Maragatería. Incluye tres pueblos, cuya población 
conjunta ha descendido de 2.000 habitantes en el año 1900 a 578 en 2012, derivando en niveles de ruina elevados debido a diferentes evoluciones sociohistóricas. Lagunas tuvo una fuerte presencia de la elite comerciante maragata, predominando así la arquitectura monumental característicamente maragata, de planta cuadrada, normalmente abandonada desde hace más de un siglo. Tras la emigración masiva de las elites maragatas a comienzos del siglo XX, la mayor parte de las viviendas se convierten en ruinas por su alto coste de mantenimiento $(18,6 \%)$, o bien son restauradas por neorrurales procedentes de centros urbanos con elevada capacidad adquisitiva $(19,5 \%)$ (Tabla 3$)$. La población local, eminentemente campesina y envejecida, se mantiene en casas tradicionales $(44,3 \%)$ con un escaso porcentaje de casas en transición o modernas $(17,7 \%)$. Por su parte, los tres barrios de Val de San Román reflejan una estrategia de poblamiento dirigida a aprovechar los recursos agropecuarios por una población campesina donde la presencia de la elite maragata fue mínima. El éxodo rural de mediados del siglo XX llevó a un abandono importante de las casas $(19,1 \%)$ y los escasos beneficios del trabajo agrícola a la prevalencia de la casa tradicional $(34,8 \%)$ sobre la moderna $(7,0 \%)$. Las casas restauradas $(21,7 \%)$ son escasamente monumentales y están realizadas básicamente por emigrantes locales que regresan al pueblo para jubilarse o como segunda vivienda.

En Val de San Lorenzo la presencia de la elite maragata fue mínima, pero el desarrollo de una artesanía textil y su industrialización $(4,8 \%$ de edificios industriales) permitió la acumulación de capitales y el mantenimiento demográfico local (solo 1,4\% de ruina) (Alonso González 2013:421-443).
Las casas tradicionales $(28,4 \%)$ se han reutilizado funcionalmente como establos o espacios de almacenamiento. Desde mediados del siglo XX, el incremento de las rentas permitió una transición a la materialidad moderna $(18,4 \%$ de casas en transición) y la construcción de casas modernas de nueva planta $(22,9 \%)$. Este proceso llevó a la ruptura del paisaje visual homogéneo del pueblo a medida que los procesos de individualización derivados de la división del trabajo provocada por la industrialización acabaron con el ethos comunitario. Mientras los empresarios capitalistas construyeron casas modernas de ladrillo y cemento, los trabajadores que formaron una cooperativa incorporaron materiales modernos y añadieron nuevos espacios a sus casas de forma orgánica (baños, cocinas modernas, garaje) a medida que podían permitírselo. Los materiales vernáculos, como la piedra, pasaron a ser símbolos de pobreza y se ocultaban persistentemente bajo encalados o cemento.

Cuando en la década de 1980 España ingresa en el Mercado Común Europeo la industria decae, pero la acumulación de capital permite dar el salto a una economía terciaria basada en el binomio turismopatrimonio. Se aplican así medidas urbanísticas, museísticas y se subvenciona con fondos estructurales europeos la apertura de restaurantes y casas rurales (Benito del Pozo y Alonso González 2012). Este proceso implicó la generación de un estilo patrimonial híbrido que distintos actores sociales aplicaron en todo el pueblo. Se conformó así un metapatrón que organizaba las indeterminaciones -de otro modo caóticas-de la vida social, reduciendo la continuidad y heterogeneidad diacrónica a una forma de identidad estable (Herzfeld 1992). Tres ejemplos sintéticos bastan para encapsular el proceso.

Tabla 3. Casas por categorías en el caso de estudio de Maragatería (León). Houses by category in the case study of Maragatería (León).

\begin{tabular}{lccccccc}
\hline & $\begin{array}{c}\text { Casas } \\
\text { tradicionales }\end{array}$ & $\begin{array}{c}\text { Casas en } \\
\text { transición }\end{array}$ & $\begin{array}{c}\text { Casas } \\
\text { modernas }\end{array}$ & $\begin{array}{c}\text { Casas } \\
\text { restauradas }\end{array}$ & Ruinas & $\begin{array}{c}\text { Edificios } \\
\text { industriales }\end{array}$ & Total \\
\hline Lagunas de & 50 & 17 & 2 & 22 & 21 & 4 & 116 \\
Somoza & $43,1 \%$ & $14,7 \%$ & $1,7 \%$ & $19 \%$ & $18,1 \%$ & $3,4 \%$ & \\
Val de & 101 & 66 & 78 & 81 & 5 & 17 & 348 \\
San Lorenzo & $29,03 \%$ & $18,96 \%$ & $22,42 \%$ & $23,27 \%$ & $1,44 \%$ & $4,88 \%$ & \\
Val de & 40 & 20 & 8 & 25 & 22 & 5 & 120 \\
San Román & $33,3 \%$ & $16,7 \%$ & $6,7 \%$ & $20,8 \%$ & $18,3 \%$ & $4,2 \%$ & \\
\hline
\end{tabular}


La nueva reglamentación urbana prohibió la presencia de bancos o poyos de piedra en las puertas de las casas, espacios habituales de reunión e interacción social que reforzaban los vínculos comunitarios y la tradicional permeabilidad del espacio habitado. Las puertas estaban siempre abiertas y los vecinos solían entrar y salir en casas ajenas. La familia y la casa entraban en relación metonímica con la comunidad con el poyo como elemento importante. La supresión de este elemento refleja una búsqueda por purificar lo urbano y subrayar la importancia de la fachada como elemento de valor estético patrimonializado, que pasa de área permeable a dispositivo metafórico-representacional y frontera liminal que separa interior y exterior (Zaera-Polo 2008). Se separa así el núcleo familiar privado del ámbito comunal convertido en espacio público. Igualmente, la contemplación estética, como metapatrón patrimonial estático y atemporal, se impone sobre la vida y el devenir.

La construcción del Centro de Interpretación Textil La Comunal implicó la transformación de una antigua fábrica comunal de ladrillo, cemento y cubierta de fibrocemento en un edificio patrimonializado. Se cambió el tejado, se encaló el cemento de la fachada y se pintó con colores vernáculos, se sacó a relucir el zócalo de piedra y la madera sustituyó al metal en las puertas. Bombillas dentro de cencerros de vaca iluminan la colección. Finalmente, neorrurales urbanos compran y restauran casas en el centro histórico $(20,4 \%)$, buscando materializar la representación cultural de la casa monumental maragata (escasamente presente en Val de San Lorenzo) en sus construcciones. A la vez, las clases pudientes locales que habían abrazado la materialidad de la casa moderna comienzan a construir casas posmodernas $(5,4 \%)$, tanto para viviendas familiares como para negocios de turismo auspiciados por fondos europeos de desarrollo rural.

Estas casas de nueva planta, representación última de la sublimación posmoderna, se construyen con materiales modernos pero se recubren de piedra y teja tradicional, e imitan formas monumentales maragatas. Su distribución espacial alrededor del pueblo (Figura 10) refleja su voluntad de aislamiento y diferenciación, además de la necesidad funcional de superficie para piscinas, garajes y jardines. Así, los usos funcionales modernos se compaginan con

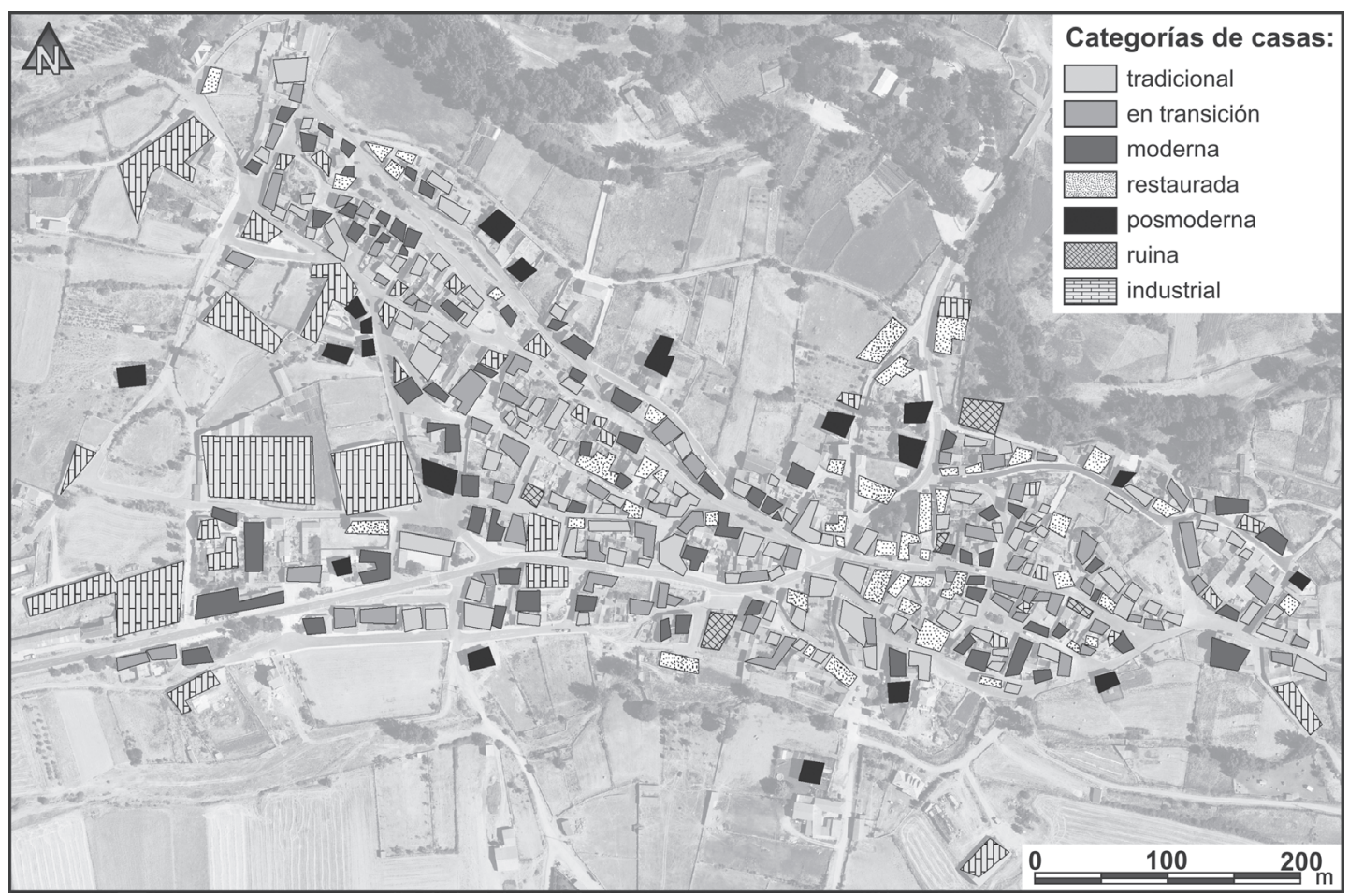

Figura 10. Plano de Val de San Lorenzo con la distribución de las casas analizadas según las categorías establecidas. Map of Val de San Lorenzo with the spatial distribution of the houses studies according to our categories. 
la voluntad de usar la casa y su fachada como metáfora representacional del núcleo familiar, como ente autónomo e individualizado dentro de la comunidad. Mientras, las casas tradicionales, en transición, e incluso modernas, presentan patios y espacios interiores que pueden ser considerados como "sedimentos" (cf. Haber 2011:26-27): acumulaciones de materiales variados como vidrios, metales o aperos de labranza sin intención estética. En cambio, las casas posmodernas se conciben como "monumentos": mecanismos representacionales donde prima la visión y no se acumulan materiales, sino que se disponen racional y ordenadamente de cara a la exhibición. Así, se exponen en forma ostentosa materiales de un pasado que se ha superado simbólicamente: arados, yugos, trillos, etc. Se produce así una codificación superlativamente moderna: la apropiación material de restos materiales del pasado y su desplazamiento temporal hacia un período remoto (Grossberg 1996). Es lo que Deleuze llama una "disyunción inclusiva", una afirmación de la diferencia, de aquello que remite y relaciona a dos entidades la una a la otra en tanto que diferentes y las ordena jerárquicamente: el pasado campesino es el objeto de enunciación pasivo y reificado, y el individuo posmoderno el sujeto activo y enunciativo (Alonso González 2012).

\section{Conclusiones}

Nuestra investigación da cuenta del "devenir" de las formas en las que dos grupos sociales entran en relación con sus casas y comunidades. Esta transformación se produce a distintos ritmos y varía entre los distintos actores sociales participantes que intervienen de acuerdo con sus patrones estructurados de movilidad, acceso a recursos culturales y económicos y, en definitiva, a los distintos modos $\mathrm{y}$ formas de existencia que permiten adquirir estos recursos (Briones 2005). Concebimos el devenir de estos grupos a partir de una transformación del patrón provisionalmente dominante de la tradición preindustrial hacia formas de relacionalidad posmodernas. Estas funcionan como "atractores" o categorías abstractas hacia las que los actores sociales tienden y no como fases deterministas de tipo evolutivo. Sin embargo, percibimos cierta propensión de los actores sociales a moverse desde identidades relacionales en los que predominan factores funcionales y productivos que reproducen un ethos comunitario y una relación metonímica entre la casa y la familia, hacia formas posmodernas e individualizadas propias de grupos urbanos con una mayor división social del trabajo (Hernando Gonzalo 2012).

Este proceso secciona las relaciones entre familia, casa y comunidad, reproduciendo normas de estilo y distinción por medio del uso de la casa como dispositivo representacional y metafórico además de objeto de consumo vinculado al tiempo libre y el ocio. La casa pasa así de constituirse como "sedimento", vinculado a usos funcionales y en relación metonímica con la realidad, a ser un "monumento" que vehicula el imaginario de habitantes urbanos con alto grado de individualización. Estos utilizan la fricción entre jerarquías globales de valor patrimonial y la mercantilización de etnicidades históricas para reforzar la construcción de su identidad y diferenciarse de los otros mediante el uso simbólico de la cultura material. La segmentación del vínculo afectivo entre la casa y la familia facilita igualmente su conversión en mercancía o monumento, agilizando los procesos de compraventa inmobiliaria: la casa se convierte en una inversión tanto económica como biopolítica, asociándose a una forma de vida específica.

Lejos de hablar de simples procesos de hibridación, o proponer un modelo evolutivo determinista en fases, nuestro estudio muestra las múltiples temporalidades, ritmos y cosmovisiones de distintos grupos en relación con conformaciones específicas de la materialidad. Así, observamos cómo durante la modernidad se construyó socialmente una representación cultural de la otredad de maragatos y vaqueiros d'alzada (proceso de abstracción), a la vez que se produjo la obliteración de su alteridad real en términos socioculturales que derivaba de procesos históricos específicos (proceso de destrucción). Durante la posmodernidad se produce sin embargo la materialización de la diferencia, el intento de vincularse simbólicamente mediante la cultura material con la representación cultural de aquellas identidades culturales que, a día de hoy, ya no existen. Esto ocurre principalmente en el caso de Maragatería, donde hay una arquitectura monumental a la que poder vincularse, pero no en el caso de los vaqueiros d'alzada, cuya arquitectura resulta escasamente monumental para las necesidades de ostentación de gentes urbanas individualizadas. Evidentemente, estos procesos de cambio cultural conllevan la imposición hegemónica de valores de clases adineradas urbanas en lo rural, ya que 
no se trata solo de que producimos objetos individualizados porque nosotros lo estamos, sino de que a través del uso rutinario de esos objetos nos vamos individualizando cada vez más, por lo que en el futuro generamos objetos crecientemente individualizados que potenciarán la lógica de la tendencia social (Hernando Gonzalo 2012:20).

Así, la investigación de la domesticidad mediante metodologías híbridas y perspectivas interdisciplinares permite explorar procesos contemporáneos de cambio cultural. Estos reflejan una clara tendencia a la disolución de las fronteras entre las esferas de la producción y el consumo, el ocio y la cultura, en la que se busca el capital simbólico tanto a nivel individual como colectivo a partir de diferencias que aportan valor. Solo así se entienden la construcción de falsas viviendas maragatas en Val de San Lorenzo, la creación de una Comarca Vaqueira en Asturias en un área donde la herencia vaqueira prácticamente ha desaparecido y que a la vez deja fuera municipios como Somiedu donde esta se ha preservado mejor, o de parques naturales que buscan preservar tradiciones que no existen y que más bien emergen y/o se reinventan con las propias intervenciones institucionales.

En este sentido, cabe remarcar el desconocimiento y falta de interés institucional con relación a las consecuencias de sus propias legislaciones y planes de actuación, debido a la profunda ignorancia de estos procesos de cambio cultural. Esto deriva de la falta de estudios de carácter antropológico, etnográfico o histórico como el que aquí se presenta. En un marco de gobernanza neoliberal se fomenta el libre flujo de capitales y la producción de valor a partir de cualquier posible recurso cultural, con escaso interés por la cuestión de la "autenticidad", de las formas de vida locales y la existencia de patrones de alteridad real en zonas rurales. La gestión mediante el tropo o metrapatrón del patrimonio de las zonas rurales a partir de criterios urbanos impone formas de gestión y vocabularios exógenos, a la vez que, entre otros procesos, secciona las relaciones entre casas y formaciones sociales. En última instancia, se produce una colonización de los "otros internos" que lleva a la preponderancia de cosmovisiones foráneas. Esto se realiza no solo mediante la imposición de valores estéticos y vitales, sino también mediante la gentrificación de espacios rurales que tienden a despoblarse. Así, los paisajes y la arquitectura doméstica en pueblos como los analizados en Somiedu y Val de San Lorenzo, pero también en otros muchos de la geografía española, son adscritos a la función pasiva de "ser observados" como "bellos", "vernáculos" y "diferentes" abandonando sus funciones previas en términos vitales y productivos.

Agradecimientos: Los autores agradecen especialmente a todos los entrevistados para la realización de esta investigación. Igualmente, a los evaluadores que han posibilitado su mejora en varios aspectos.

\section{Referencias Citadas}

Acevedo y Huelves, B. 1893. Los Vaqueiros de Alzada en Asturias. Imprenta del Hospicio Provincial, Oviedo.

Alonso González, P. 2009. Etnoarqueología y Gestión del Patrimonio Cultural: Maragatería y Val de San Lorenzo. Universidad de León, León.

----2012. Flanqueando el procesualismo y post-procesualismo: Arqueología, teoría de la complejidad y la filosofía de Gilles Deleuze. Complutum 23:13-32.

----2013. The Heritage Machine: A Heritage Ethnography in Maragatería (Spain). Tesis Doctoral, Departamento de Historia, Universidad de León, León.

Alonso González, P. y D. González Álvarez 2014. Houses and cultural change: An archaeological methodology for the exploration of the built environment in Contemporary rural Spain. En Designating Place: Archaeological Perspectives on Past Built
Environments, editado por M. Baumanova, K. Pauknerová, G. Higginbottom y H. Stöger, en prensa.

Aragón y Escacena, F. 1902. Breve Estudio Antropológico acerca del Pueblo Maragato. Fortanet, Madrid.

Benito del Pozo, P. y P. Alonso González 2012. Industrial heritage and place identity in Spain: From monuments to landscapes. Geographical Review 102:446-464.

Binford, L.R. 1978. Nunamiut Ethnoarchaeology. Academic Press, New York.

Briones, C. 2005. Formaciones de alteridad: contextos globales, procesos nacionales y provinciales. En Cartografías Argentinas: Políticas Indígenas y Formaciones Provinciales de Alteridad, editado por C. Briones, pp. 9-40. Antropofagia, Buenos Aires.

Buchli, V. y G. Lucas (eds.) 2001. Archaeologies of the Contemporary Past. Routledge, London. 
Callahan, W.J. 1972. Honor, Commerce and Industry in Eighteenth-Century Spain. Baker Library, Harvard Graduate School of Business Administration, Boston.

Caro Baroja, J. 2003. Los Pueblos de España, 2. Alianza, Madrid. Castañeda, Q. 2008. The "Ethnographic Turn" in Archaeology. Research Positioning and Reflexivity in Ethnographic Archaeologies. En Ethnographic Archaeologies. Reflections on Stakeholders and Archaeological Practices, editado por Q. Castañeda y C.N. Matthews, pp. 25-61. AltaMira Press, Plymouth.

Cátedra Tomás, M. 1989. La Vida y el Mundo de los Vaqueiros de Alzada. CIS, Madrid.

Comaroff, J.L. y J. Comaroff 2009. Ethnicity, Inc. The University of Chicago Press, Chicago.

Deleuze, G. 1993. The Fold: Leibniz and the Baroque. University of Minnesota Press, Minneapolis.

Egocheaga Rodríguez, J.E. y R. García González 2003. Análisis dermatoglífico de la población vaqueira. En Antropología y Biodiversidad, Vol. II, editado por A. Malgosa, R.M. Nogués y M.P. Aluja, pp. 527-533. Ediciones Bellaterra, Barcelona.

Freeman, S.T. 2011. Recursos y temática para el trabajo de campo en España, 1962-1990. En Lugares, Tiempos, Memorias: la Antropología Ibérica en el Siglo XXI, editado por L. Díaz Viana, O. Fernández Álvarez y P. Tomé Martín, pp. 51-64. Universidad de León, León.

García Martínez, A. 1988. Los Vaqueiros de Alzada de Asturias. Un Estudio Histórico-Antropológico. Principado de Asturias, Oviedo.

González Álvarez, D. 2011. Casas nuevas para nuevos tiempos. Cambio cultural y materialidad en las brañas-pueblo de Somiedu (Asturias). Actas de las II Jornadas de Jóvenes en Investigación Arqueológica (JIA 2009), tomo II, editado por OrJIA, pp. 775782. Libros Pórtico, Zaragoza.

González Ruibal, A. 2003a. Etnoarqueología de la Emigración. El Fin del Mundo Preindustrial en Terra de Montes (Galicia). Diputación de Pontevedra, Pontevedra.

----2003b. La Experiencia del Otro. Una Introducción a la Etnoarqueología. Akal Arqueología, Madrid.

----2005. The need for a decaying past: an archaeology of oblivion in contemporary Galicia (NW Spain). Home Cultures 2:129-152.

----2008a. De la Etnoarqueología a la Arqueología del presente. En Mundos Tribales. Una Visión Etnoarqueológica, editado por J. Salazar, I. Domingo, J.M. Azkárraga y H. Bonet, pp. 16-27. Museu de Prehistòria de València, Valencia.

----2008b. Time to destroy. An archaeology of supermodernity. Current Anthropology 49:247-279.

Grossberg, L. 1996. Identity and cultural studies: is that all there is? En Questions of Cultural Identity, editado por P. Du Gay y S. Hall, pp. 87-107. SAGE, London.

Guattari, F. 1995. Chaosmosis: an Ethico-Aesthetic Paradigm. Indiana University Press, Bloomington.

Haber, A. 2011. La Casa, las Cosas y los Dioses. Arquitectura Doméstica, Paisaje Campesino y Teoría Local. Editorial Brujas, Córdoba.
Hamilakis, Y. 2011. Archaeological ethnography: A multitemporal meeting ground for archaeology and anthropology. Annual Review of Anthropology 40:399-414.

Hernando Gonzalo, A. 2006. Arqueología y globalización: el problema de la definición del" otro" en la postmodernidad. Complutum 17:221-234.

----2012. La Fantasía de la Individualidad. Sobre la Construcción Sociohistórica del Sujeto Moderno. Katz, Buenos Aires.

Hernando Gonzalo, A. y A. González Ruibal 2011. Fractalidad, materialidad y cultura: un estudio etnoarqueológico de los AwáGuajá de Maranhão (Brasil). Revista Chilena de Antropología 24:9-61.

Herzfeld, M. 1992. Metapatterns: Archaeology and the uses of evidential scarcity. En Representations in Archaeology, editado por J. Claude Gardin y C. Spalding Peebles, pp. 66-86. Indiana University Press, Bloomington.

----2010. Engagement, gentrification, and the neoliberal hijacking of history. Current Anthropology 51(S2):S259-S267.

Hors, P. 1951. Seroantropología de leoneses y maragatos. Hematología y Hemoterapia 1:99-100.

Ingold, T. 2000. The Perception of the Environment. Essays on Livelihood, Dwelling and Skill. Routledge, London.

Lardizábal y Uribe, M. 1786. Apología por los Agotes de Navarra y los Chuetas de Mallorca, con una Breve Digresión a los Vaqueiros de Asturias. Imprenta de la viuda Ibarra, Madrid.

Larruga, J.M., F. Díez, F.M.Pinto, C. Flores y A.M. González 2001. Mitochondrial DNA characterisation of European isolates: The Maragatos from Spain. European Journal of Human Genetics 9:708-716.

Latour, B. 2005. Reassembling the Social: An Introduction to Actor-Network-Theory. Oxford University Press, Oxford.

Lordon, F. 2006. L'Intérêt Souverain: Essai d'Anthropologie Économique Spinoziste. Découverte, Paris.

Melis Maynar, A. 1987. Los maragatos entre la tradición y el mito. En Invitación a la Antropología Cultural Leonesa, editado por J. González Arpide, pp. 82-113. Universidad de León, León.

Meskell, L. 2012. The Nature of Heritage: The New South Africa. Wiley-Blackwell, Malden.

Miller, D. 1998. Material Cultures: Why Some Things Matter. Routledge, Chicago.

Miner Otamendi, J.M. y L. Martínez 1978. Los Pueblos Malditos: Agotes, Pasiegos, Vaqueiros de Alzada, Maragatos, Chuetas. Espasa-Calpe, Madrid.

Ortiz García, C. 1999. The uses of folklore by the Franco Regime. Journal of American Folklore 112(446):479-496.

Rose, M. 2011. Secular materialism: a critique of earthly theory. Journal of Material Culture 16:107-129.

Rubio Pérez, L.M. 2003. Los Maragatos. Origen, Mitos y Realidades. Monte Casino, Zamora.

Rullani, E. 2006. Economia della Conoscenza: Creatività e Valore nel Capitalismo delle Reti. Carocci, Roma. 
Sarmiento, F.M. 1787. Discurso crítico sobre el origen de los maragatos. En Semanario Erudito, editado por B. Román, pp. 175-214. Madrid.

Shaviro, S. 2009. Without Criteria: Kant, Whitehead, Deleuze, and Aesthetics. MIT Press, Cambridge.

Sørensen, M.L.S. 2009. Between the lines and in the margins: Interviewing people about attitudes to heritage and identity. En Heritage Studies: Methods and Approaches, editado por M.L.S. Sørensen y J. Carman, pp. 164-177. Routledge, New York.
Tilley, C. 1991. Material Culture and Text: The Art of Ambiguity. Routledge, London.

Viejo-Rose, D. 2011. Reconstructing Spain: Cultural Heritage and Memory After Civil War. Sussex Academic Press, Brighton.

Zaera-Polo, A. 2008. The Politics of the envelope. A political critique of materialism. 17:76-105.

Zarankin, A. 1999. Casa tomada, sistema, poder y vivienda doméstica. En Sed Non Satiata; Teoría Social en la Arqueología Latinoamericana Contemporánea, pp. 239-272. Del Tridente, Buenos Aires.

\section{Notas}

1 Para una presentación detallada de nuestra metodología ver Alonso González y González Álvarez (2014).

2 Los conceptos de tradición, modernidad y posmodernidad son concebidos, siguiendo a Guattari (1995), como "sistemas provisionalmente dominantes" más que como fases cronológicas o evolutivas. 
